\title{
Oesophageal atresia: Gastrostomy tube care, using alternatives can lead to complications too!
}

\author{
*Niraj Kumar Dipak¹, Samir Sultanbhai Sheikh ${ }^{2}$, Anita Srinivasan ${ }^{3}$ \\ Sri Lanka Journal of Child Health, 2016; 45(4): 283-285 \\ DOI: http://dx.doi.org/10.4038/sljch.v45i4.7975 \\ (Key words: esophageal atresia, gastrostomy tube, counselling, complications)
}

\section{Introduction}

Many types of complications of gastrostomy tube have been documented, including tube obstruction and dislodgement, malpositioning of replaced tubes, stomal leak, and tube migration and prolapse with or without gastric outlet obstruction and intussusception $^{1-3}$. These complications increase especially when Foley catheter is being used as gastrostomy tube. When in cases such as long gap oesophageal atresia, neonates are discharged with the gastrostomy tube, the caregivers feel a lack of knowledge regarding the care of their child with gastrostomy tube ${ }^{4}$. Some of the researchers have mentioned that a well-planned teaching protocol for caregivers is required to reduce various morbidities in children with gastrostomy tube feeding ${ }^{5-7}$.

\section{Case report}

A $1750 \mathrm{~g}$ male baby was born at 36 weeks of gestation to a primigravida mother. Antenatal period was uneventful except for the development of progressive polyhydramnios beyond 34 weeks of gestation. At birth, baby was diagnosed as having a long gap oesophageal atresia. Screening for associated cardiac, renal and cerebral anomalies was negative. Baby underwent feeding gastrostomy on day 2 of life and Foley catheter was placed as the feeding gastrostomy tube. Trophic feed was started which was escalated gradually. On day 11 of life, cervical oesophagostomy was done. On day 21 the baby was discharged, while being still fed with gastrostomy tube. On day 24 of life,

'Lecturer, ${ }^{2}$ Associate Professor, ${ }^{3}$ Resident,
Department of Neonatology, Seth GS Medical
College and KEM Hospital, Acharya Donde Marg,
Parel, Mumbai, Maharashtra, India
${ }^{*}$ Correspondence: neonatalfundas@gmail.com

(Received on 30 March 2015: Accepted after revision on 22 May 2015)

The authors declare that there are no conflicts of interest

Personal funding was used for the project.

Open Access Article published under the Creative Commons Attribution CC-BY (CC) (P) the baby was readmitted to the neonatal intensive care unit with progressively increasing abdominal distension, apnoeic episodes and poor peripheral pulses. He was put on mechanical ventilation on synchronised intermittent mandatory ventilation plus pressure support ventilation and vasopressors were started. X-ray showed huge gastric dilation with some evidence of generalized bowel dilation raising suspicion of gastric outlet obstruction (Figure 1).

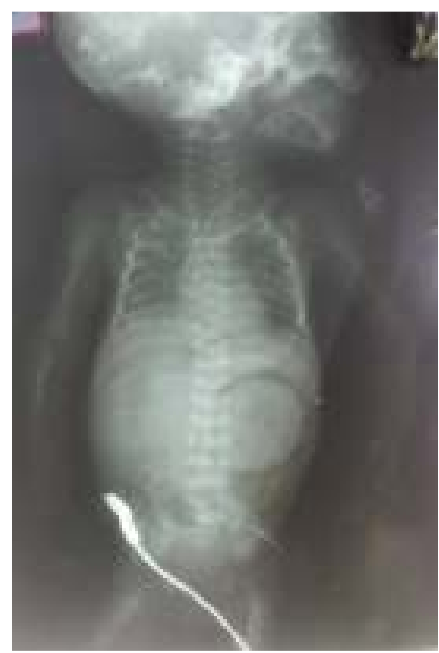

Figure 1: X-ray of abdomen

The balloon of Foley catheter (used as gastrostomy tube) when aspirated, showed $15 \mathrm{ml}$ milk (Figure 2) instead of $3 \mathrm{ml}$ of normal saline (NS). Foley catheter balloon is filled with NS as it is helpful for tube fixation and keeping gastric-stoma patent.

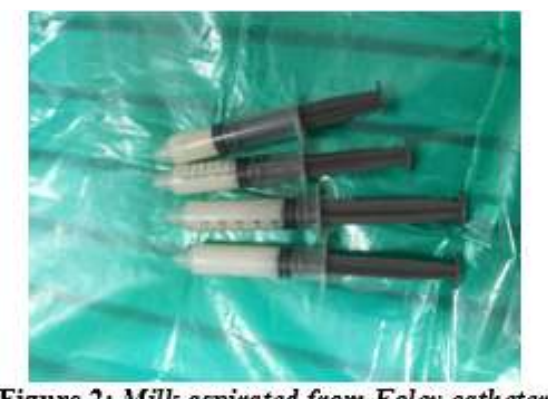

Figure 2: Milk aspirated from Foley catheter

After deflation of balloon (Figure 3) baby started improving and vasopressors were gradually tapered and withdrawn. 


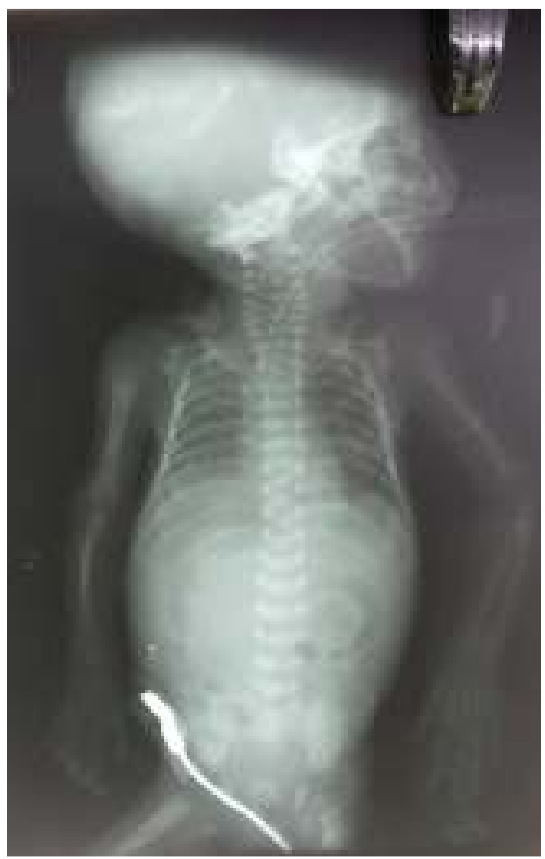

Figure 3: After deflation of balloon

The baby was extubated after 3 days of ventilation. Baby was discharged after 7 days of hospitalization on ensuring reinforcement of training of parents for gastrostomy tube care. At the time of writing this article, baby is under follow up, on feeding with gastrostomy tube, awaiting definitive repair and thriving well.

\section{Discussion}

Gastrostomy tube insertion is a part of the surgical management of oesophageal atresia. Cervical oesophagostomy and gastrostomy is performed in neonates with large gap in proximal and distal parts of oesophagus or when it is not possible to perform primary repair due to several reasons. Feeding is continued through gastrostomy tube until definitive repair. Neonates are sent home with gastrostomy tube and the caregivers are supposed to give feeding at home through the tube. Prior to discharge it is the nurse's responsibility to ensure that the parents can provide safe, competent care to their child with oesophagostomy and gastrostomy tube feeding ${ }^{8}$.

Complications of gastrostomy tube (1-14\%) include those related to surgical procedures, like wound infection, intra-abdominal leak and pneumoperitoneum (35\%) and the problems related to gastrostomy creation, e.g. peristomal dermatitis, bleeding, granuloma and gastro-oesophageal reflux. Minor complications like tube migration and secondary gastrointestinal obstruction or tube blockage can be prevented by good nursing care including, repeated skin length measuring, checking balloon function and tube irrigation ${ }^{9-13}$.
These complications increase when a small size standard gastrostomy tube is not available for neonates and Foley's catheter is being used instead since it has 2 channels and caregivers need to be trained appropriately about the use of each channel. In the present case due to lack of proper counselling of the care providers regarding the feeding through the gastrostomy tube, the neonate was being fed through the port which was meant for balloon inflation. As such a complication has never been reported in the literature with use of Foley catheter as a gastrostomy tube, we want to highlight the importance of proper counselling to the care givers, so that such complications can be prevented. Sukrawal et $\mathrm{al}^{8}$ conducted an operational study with the objective of developing the skills of caregivers in providing home care to neonates with gastrostomy tube feeding. They emphasized on the development of a separate multidisciplinary clinic for children with gastrostomy tube to deal with the problems faced by these children and their caregivers. There should be a specialist nurse to develop knowledge and skills in caregivers of children with gastrostomy tube ${ }^{8}$.

\section{References}

1. Haws E, Sieber W, Kiesewetter W. Complications of tube gastrostomy in infants and children. Annals of Surgery 1966; 164:284-90.

http://dx.doi.org/10.1097/00000658-

196608000-00015

PMid: 5915939 PMCid: PMC1477235

2. Gowen G. The management of complications of Foley feeding gastrostomies. Am Surg 1988; 54:582-5. PMid: 3137855

3. Wolf E, Frager D, Beneventano T. Radiologic demonstration of important gastrostomy tube complications. Gastrointestinal Radiology 1986; 11:206.

http://dx.doi.org/10.1007/BF02035025

PMid: 3943673

4. Spalding K, Mckeveer P. Mothers experiences for children with disabilities who require a gastrostomy tube. Journal of Pediatric Nursing 1998; 13(4):234-43. http://dx.doi.org/10.1007/BF02035025 PMid: 3943673

5. Rouse L., Herrington P, Assey $\mathrm{J}$ et al. Feeding problems, gastrostomy and families: a qualitative pilot study. British 
Journal of Learning Disabilities 2002; 30(4): 122-8.

http://dx.doi.org/10.1046/j.14683156.2002

.00149.x

6. Koulentaki M, Reynolds N, Steinke D et al. Eight years' experience of gastrostomy tube management. Endoscopy 2002; 34(12):9415.

http://dx.doi.org/10.1055/s-2002-35843

PMid: 12471535

7. Tracey DL, Patterson GE. Care of the gastrostomy tube in the home. Home Healthcare Nurse 2006; 24(6): 381-6. http://dx.doi.org/10.1097/0000404520060 6000-00009

8. Sukrawal P, Kaur R, Rao K. Skills development of caregivers in homecare of neonates with gastrostomy tube feeding. Nursing and Midwifery Research Journal 2013; 9:81-9.

9. Holder TM, Leape LL, Ashcraft KW. Gastrostomy: Its use and dangers in pediatric patients. New England Journal of Medicine 1972; 286:1345-7.

http://dx.doi.org/10.1056/NEJM197206222862 506

PMid: 4554838
10. Grunow JE, Al-Hafidh AD, Tunell WP. Gastro-oesophageal reflux following percutaneous endoscopic gastrostomy in children. Journal of Pediatric Surgery 1989; 24:42-5.

http://dx.doi.org/10.1016/S00223468(89)8 0298-2

11. Stringel G. Gastrostomy with anti-reflux properties. Journal of Pediatric Surgery 1991; 25:1019-21. http://dx.doi.org/10.1016/00223468(90)90 209-R

12. Isch JA, Rescorla FJ, Scherer LR et al. The development of gastro-oesophageal reflux after percutaneous endoscopic gastrostomy. Journal of Pediatric Surgery 1997; 32:321-3. http://dx.doi.org/10.1016/S00223468(97)9 0202-5

13. Burd RS, Price MR, Whalen TV. The role of protective anti-reflux procedures in neurologically impaired children: A decision analysis. Journal of Pediatric Surgery 2002; 37:500-6. 